\title{
Current status of Blastocystis sp. in animals from Southeast Asia: a review
}

\author{
Adedolapo Aminat Rauff-Adedotun ${ }^{1}$ (D) $\cdot$ Siti Nursheena Mohd Zain $^{2}$ (D) $\cdot$ Meor Termizi Farah Haziqah ${ }^{1}$ (iD
}

Received: 6 February 2020 / Accepted: 21 July 2020 / Published online: 20 September 2020

(C) Springer-Verlag GmbH Germany, part of Springer Nature 2020

\begin{abstract}
Blastocystis is the most frequently observed eukaryotic gastrointestinal symbiont in humans and animals. Its low host specificity and zoonotic potential suggest that animals might serve as possible reservoirs for transmission. The prevalence and subtype distributions of Blastocystis sp. in animal populations in Southeast Asia, a hotspot for zoonotic diseases, are reviewed. Recommendations for future research aimed at understanding the zoonotic role of Blastocystis are also included. Seven countries have, so far, reported Blastocystis infection in various animals, such as livestock, poultry, companion animals, and non-human primates. Pigs were the most studied animals, and there were records of $100 \%$ prevalence in pigs, cattle, and ostriches. Using polymerase chain reaction (PCR)-based approaches, twelve Blastocystis sp. subtypes (STs), namely ST1, ST2, ST3, ST4, ST5, ST6, ST7, ST8, ST9, ST10, ST12, and ST14 have been recognised infecting animals of Southeast Asia. ST1 and ST5 were the most frequently identified, and Malaysia observed the most diverse distribution of subtypes. Further investigations on Blastocystis sp. in various animal hosts, using adequate sample sizes and uniform detection methods, are essential for a better understanding of the distribution of this organism. Detailed genome studies, especially on STs shared by humans and animals, are also recommended.
\end{abstract}

Keywords Blastocystis $\cdot$ Distribution $\cdot$ Prevalence $\cdot$ Subtypes $\cdot$ Animals $\cdot$ ASEAN

\section{Introduction}

Blastocystis sp. is a ubiquitous intestinal protistan parasite found in a wide range of animals, including humans (Tan 2004; Chandrasekaran et al. 2014). It is an anaerobic protist (Skotarczak 2018), and a member of the Stramenopiles branch of Eukarya, a complex and heterogeneous evolutionary assemblage of heterotrophic and photosynthetic protozoa (Silberman et al. 1996). Blastocystis is a polymorphic organism with four forms commonly described in literature, namely the vacuolar, granular, amoeboid, and cyst forms (Tan et al. 2002). The transmission is faecal-oral, and it commonly inhabits its host's large intestine (Tan 2008). Despite being the

Section Editor: Kevin S.W. Tan

Meor Termizi Farah Haziqah

farahhaziqah@usm.my

1 School of Biological Sciences, Universiti Sains Malaysia, 11800 USM Pulau Pinang, Malaysia

2 Institute of Biological Sciences, Faculty of Science, Universiti Malaya, 50603 Kuala Lumpur, Malaysia most widely encountered eukaryotic gastrointestinal symbiont in humans and animals (Adao and Rivera 2018), and having been described since the early 1900s, there have only been a handful of significant advances in the understanding of Blastocystis biology over the last decade (Tan 2008).

One of the primary drivers of Blastocystis ubiquity is its genetic diversity (Nieves-Ramirez et al. 2018). Based on the phylogeny of their small subunit ribosomal RNA (SSU rRNA) gene, at least 17 subtypes (STs, ST1-ST17) have been identified in a broad host range including humans, other mammals, birds, reptiles, and insects (Alfellani et al. 2013, Stensvold et al. 2012). Many of these subtypes are common to humans and animals; however, ST9 is exclusively isolated from humans (Ahmed and Karanis 2018). Currently, humans can host ten STs (STs 1-9, and ST12); nine of the ten STs have been reported in both humans and animals, hence the likelihood of zoonotic transmission (Clark et al. 2013; Mohammad et al. 2018a; Stensvold et al. 2020).

Due to the low host specificity and zoonotic potential of Blastocystis, it has been suggested that animals might serve as large potential reservoir for transmitting infection (Ahmed and Karanis 2018). The recommendation that intimate 
associations between man and animals could aid transmission of parasites has, in turn, prompted investigations on the prevalence of Blastocystis in animals from domestic environments; which would, thereby, enrich the understanding of the transmission of Blastocystis (Chuong et al. 1996). Besides, awareness on the role of wildlife in the transmission of pathogens of human health importance has grown in Asia since the emergence of diseases such as the Nipah virus, severe acute respiratory syndrome, and the avian influenza (Lee et al. 2008). These have, consequently, led to an upsurge in investigations on the epidemiology of Blastocystis sp. in several animal groups around the world, including Southeast Asia.

Zoonoses are a rising concern of Southeast Asia, a diverse region experiencing rapid social, economic, and demographic transformation (Bordier and Roger 2013). Together with agricultural practices, these factors have made this region a hotspot for zonotic diseases (Coker et al. 2011). The objective of this article was to review studies on Blastocystis sp. in this region in order to provide a clearer knowledge of its distribution in different animal hosts across Southeast Asia and to provide informed recommendations on the direction for future research including those which could ultimately lead to the understanding of the zoonotic character of Blastocystis.

\section{Methods}

Databases including Google Scholar, PubMed, and ScienceDirect were searched for articles reporting on the presence of Blastocystis in animals throughout countries of Southeast Asia. The following keywords were used: Blastocystis, STs, subtypes, distribution, epidemiology, prevalence, molecular, intestinal parasites, genetic diversity, characterization, and animals. Articles, written in English, from which samples were obtained in countries belonging to the Association of South-Eastern Asian Nations (ASEAN) and in which identification of the parasite was by either or both parasitological and molecular methods were used for this review. A total of 47 articles were, thus, found for seven ASEAN countries. Information extracted included the country, host animal, number of samples, number of samples positive for Blastocystis, subtype(s) identified, method(s) used for identification, and number of samples per subtype.

\section{Results}

In the last decade, more studies have emerged in Southeast Asia giving a clearer picture on the status and genetic diversity of Blastocystis sp. in wild animals, poultry and other birds, livestock, reptiles, arthropods, and companion animals. The 47 articles that met the inclusion criteria were studies from
Cambodia, Indonesia, Malaysia, Philippines, Thailand, Singapore, and Vietnam (summarised in Table 1). Most studies were clustered in Malaysia, Indonesia, and Thailand with foci in livestock, poultry, and wildlife. Detection methods mainly employed were the gold standard methods for Blastocystis which included conventional microscopy, in vitro culture, and Polymerase chain reaction (PCR)-based approaches. The prevalence of Blastocystis infection and the subtypes identified varied among the different taxonomic groups. The genetic diversity of Blastocystis sp. in different animals from Southeast Asia is described in Table 2.

\section{Distribution of Blastocystis sp. across ASEAN countries}

Although the occurrence of Blastocystis sp. in animals has been documented in seven countries, only five of them have reported infection in a wide range of animals. Studies on animal samples from Cambodia and Vietnam reported Blastocystis only in pigs and dogs and in pigs only, respectively. Studies from Indonesia, Malaysia, Philippines, and Thailand showed the presence of Blastocystis in livestock animals and non-human primates. The presence of infection in poultry was indicated by researches from Indonesia, Malaysia, and the Philippines.

Thus far, Blastocystis ST1, ST2, ST3, ST4, ST5, ST6, ST7, ST8, ST9, ST10, ST12, and ST14 have been recognised in animals across Southeast Asia. The most frequently identified subtypes were ST1 and ST5, with the least-observed subtypes being ST8 and ST9. The most widespread subtype was ST5, as it was found present in six of the seven countries where Blastocystis had been studied in animals. ST2 was identified in five countries, while ST9, a subtype considered unique to humans, and ST8 were detected in Malaysia only. ST12 was identified in Thailand alone. Malaysia witnessed the most diverse distribution of subtypes; a total of ten subtypes, ST1ST10, were observed. Singapore and Vietnam had the least number of studies, and in each country, only one subtype was identified. While Malaysia had the highest numbers of ST1, ST4, ST6, and ST7, the highest numbers of ST2, ST3, and ST5 were from Thailand.

\section{Distribution of Blastocystis sp. in animal hosts}

\section{Artiodactyla}

The prevalence of infection in cattle, goats, pigs, deer, sheep, and guar ranged from 14.43 to $100 \%$ (Table 1). The highest prevalence rates were found in pigs and cattle (with records of $100 \%$ ), which were also the most sampled. High prevalence of Blastocystis infection in pigs and cattle have been documented in other parts of the world (Abe et al. 2002; Masuda et al. 2018; Mokhtar and Youssef 2018; Moura et al. 2018; Greige et al. 2019). Nevertheless, Fayer et al. (2012) and 


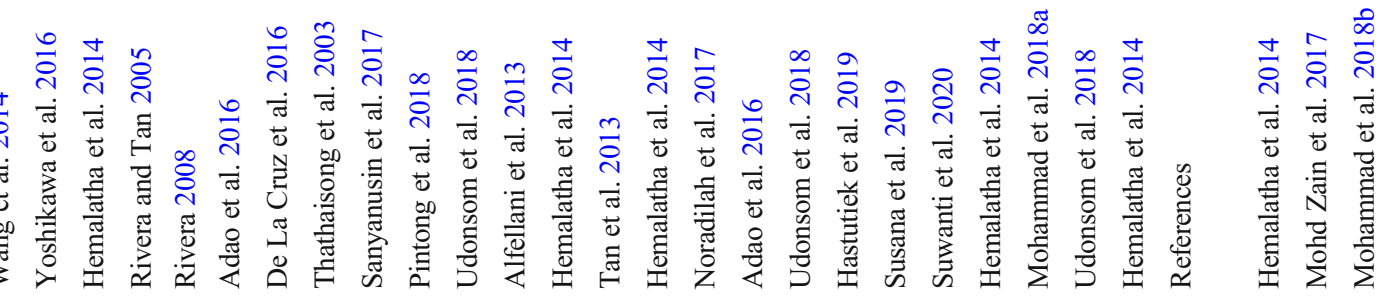
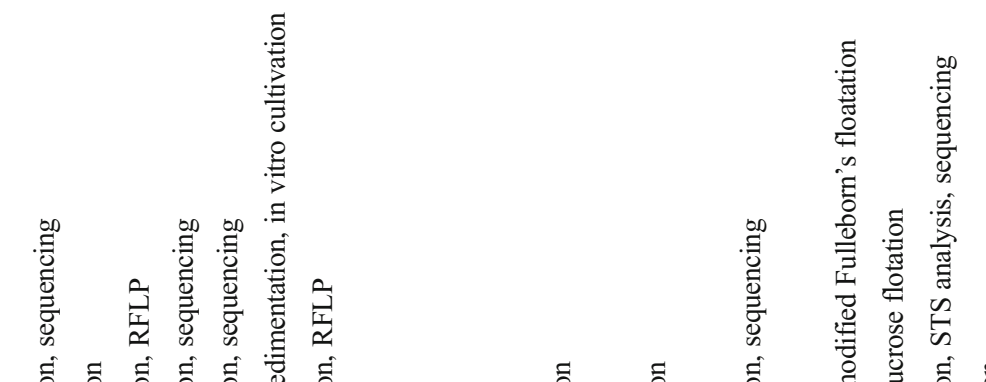

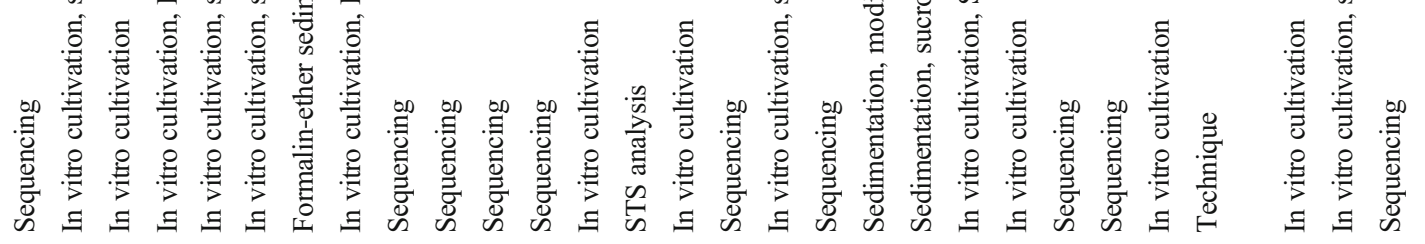

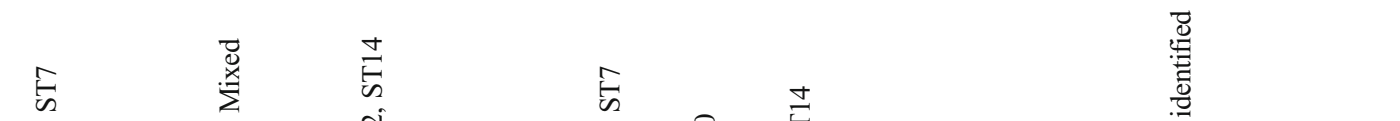

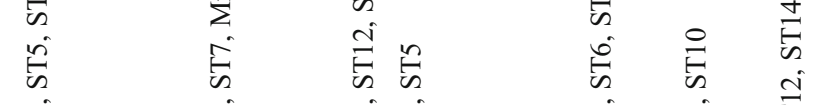

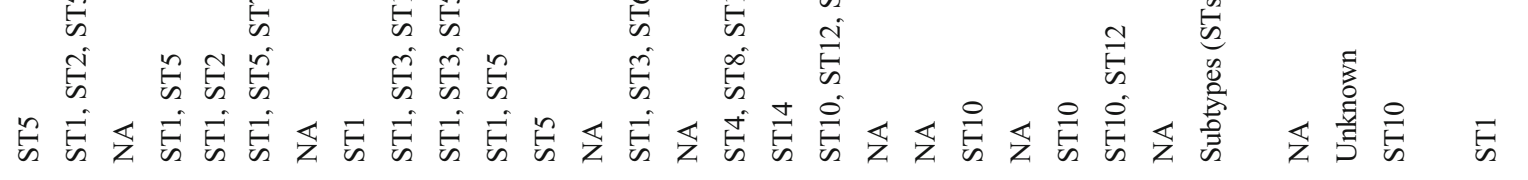

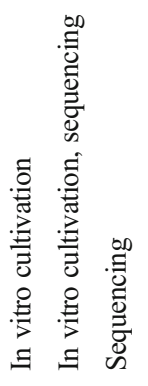

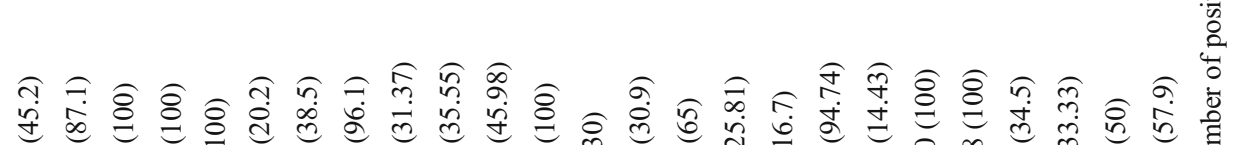

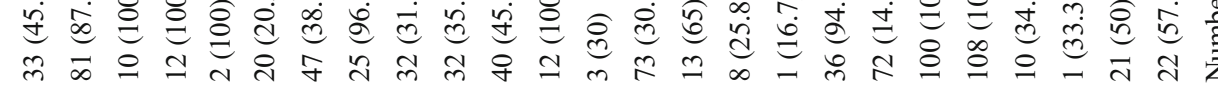

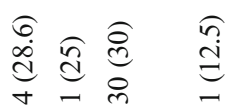
ก๙ำ

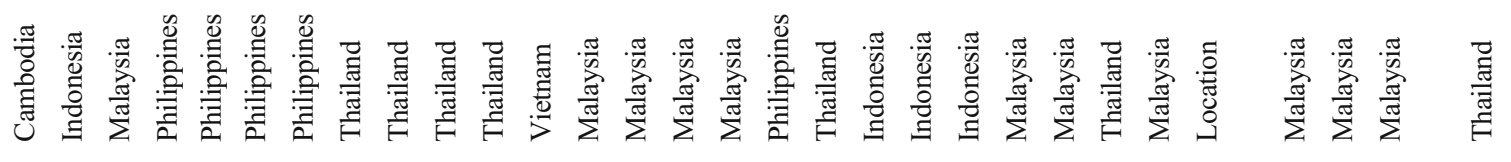
int 


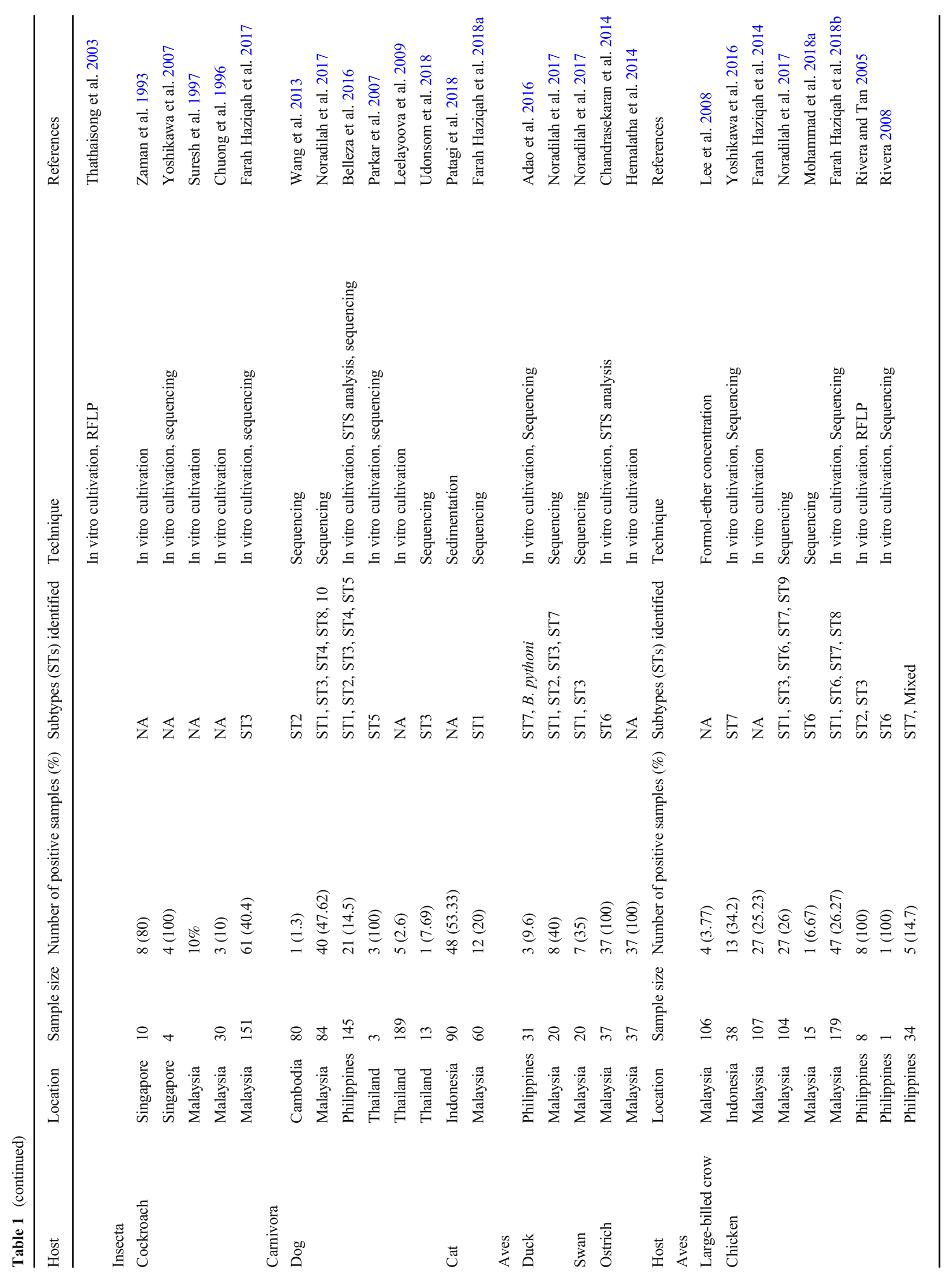




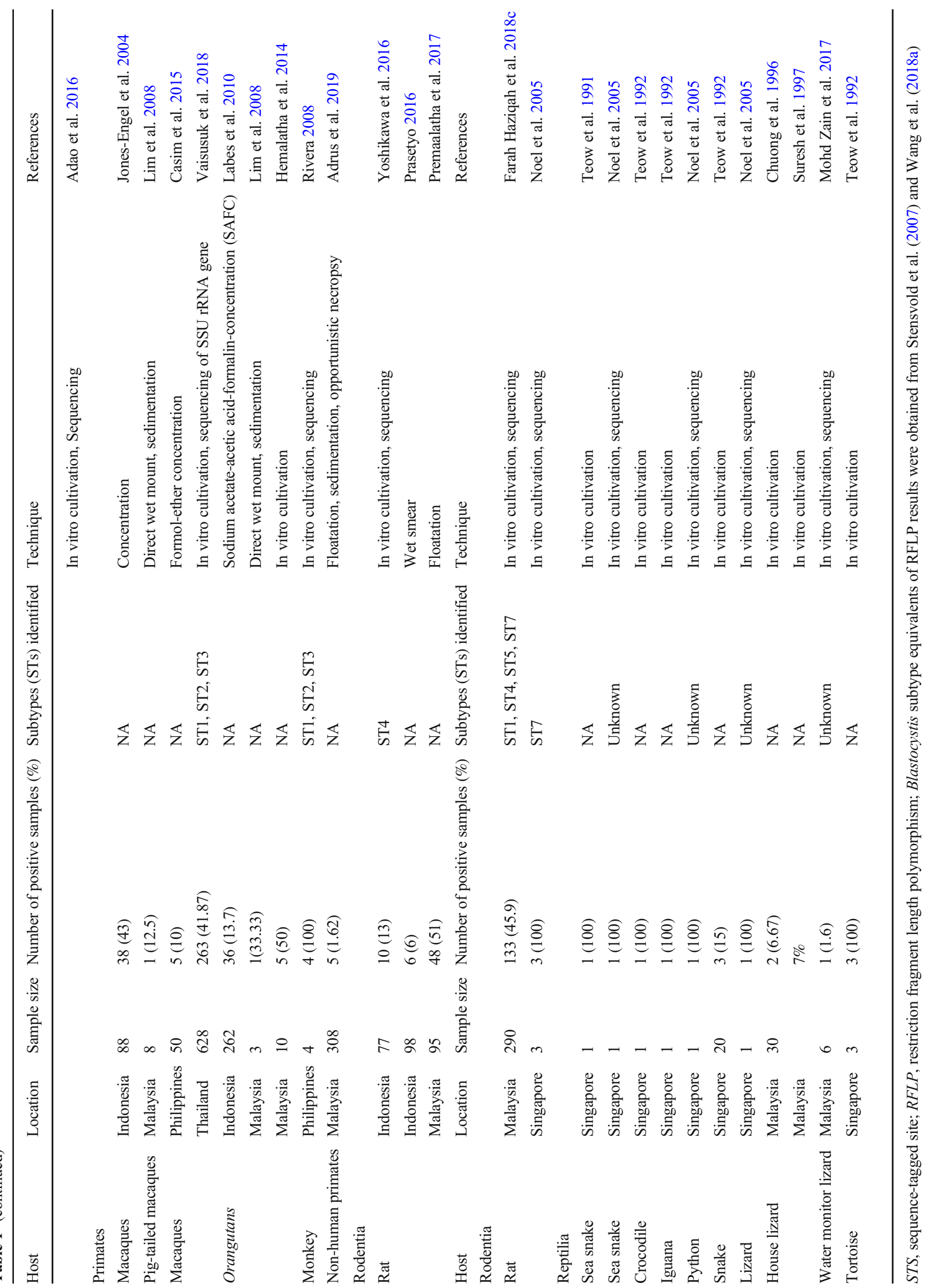


Wang et al. (2018a) respectively described infection rates as low as $19.15 \%$ and $9.5 \%$ in cattle.

Eleven subtypes of Blastocystis have been identified in Artiodactyla in ASEAN countries: ST1, ST2, ST3, ST4, ST5, ST6, ST7, ST8, ST10, ST12, and ST14 (Table 2). Most common in pigs were ST1 and ST5, which is similar to reports from Stensvold et al. (2009) and Alfellani et al. (2013). Although ST5 has been isolated in other mammalian animals, including man, pigs are referred to as the main reservoir of this subtype and a possible source of infection to man (Wang et al. 2018a). Comparable with the findings of Stensvold et al. (2009), Alfellani et al. (2013), Cian et al. (2017), and Greige et al. (2019); ST10 was quite common in cattle, goat, and deer of ASEAN countries. The frequent identification of ST10 in cattle supports suggestions that Bovidae may be the natural host for this subtype (Masuda et al. 2018). The absence of ST10 in human populations, however, suggests that cattle play a negligible role as zoonotic reservoirs of Blastocystis sp. (Greige et al. 2019). A predominance of Blastocystis ST1, ST6, and ST7 was reported in goats in Malaysia, by Tan et al. (2013), with no reports on STs beyond ST7. In this study, PCR amplification was carried out using sequenced-tagged site (STS) primers that aimed to detect ST1-ST7; this could have led to positive samples for ST8 upwards being missed out. Aside from ST10 and ST14, Song et al. (2017) mentioned the presence of ST1, ST3, ST4, ST5, and ST7 in goats in China; Alfellani et al. 2013 also reported ST3 and ST7 in goats in Libya, while Mokhtar and Youssef 2018 identified ST1 and ST4 in Egypt. The presence of ST1, ST3, and ST4 (major subtypes in humans) suggests that goats may have a role in the transmission of Blastocystis to man. The regular occurrence of ST1 and ST5 in pigs, and of ST10 in cattle, goats, and deer irrespective of the country of study, could indicate the absence of geographic limitation in the distribution of these STs.

\section{Perissodactyla}

In Southeast Asia, the presence of Blastocystis in this group of animals is rare. The only such report to date is a $12.5 \%$ prevalence in horses associated with ST3 (Thathaisong et al. 2003). ST3 has been identified as the major subtype in Perissodactyla of French zoos (Cian et al. 2017). Hemalatha et al. 2014, however, described the absence of Blastocystis in faecal samples from horses in Malaysia; Mokhtar and Youssef also reported the same from Egypt in 2018.

\section{Carnivora}

With more studies describing the presence of Blastocystis in dogs than cats (Table 1), prevalence in Carnivora ranged from 1.3 to $100 \%$. The absence of infection in dogs and cats was also reported (Chuong et al. 1996; Hemalatha et al. 2014;
Farah Haziqah et al. 2018a; Mohammad et al. 2018a). Both presence and absence of Blastocystis in dogs and cats have been documented in other regions.

Prevalence of $2.5 \%$ and $24 \%$ were described in pet and pound dogs from Brisbane, Australia, and stray dogs in India, respectively (Wang et al. 2013). However, Duda et al. (1998) had recorded a much higher prevalence $(70.8 \%)$ in Brisbane pound dogs using light microscopy only in 1998. Wang et al. (2013) attributed a likely reason for this difference to be an improved standard of care and hygiene of the pound dogs compared with that of 1998. In 1998, Duda et al. had suggested that in vitro culture conditions were not optimal for the growth of Blastocystis sp. from dogs and cats. In their analysis, faecal samples positive for Blastocystis from dogs and cats by wet mount were cultured in parallel with a human isolate of Blastocystis. MEM (minimal essential medium, Gibco BRL) failed to support the culture of Blastocystis sp. from dogs and cats but did for the human isolate. And while the growth of Blastocystis sp. from cats was unsuccessful, growth from dog samples appeared slower and less consistent than the growth of Blastocystis from human on inspissated egg slant media. Interestingly, Farah Haziqah et al. (2018a) reported a zero prevalence of Blastocystis sp. in 82 dogs and 180 cats by in vitro cultivation in modified Jones' medium, but $20 \%$ (12/60) from these cats turned out to be positive when screened by DNA barcoding. Their in vitro study showed that viable cells or cysts were destroyed under extremely acidic conditions similar to the $\mathrm{pH}$ in the gastrointestinal tract of carnivorous animals. They resolved that gastrointestinal $\mathrm{pH}$ is an important determinant of Blastocystis viability and consequently influences the epidemiology of infection within avian, mammalian, and human hosts (Farah Haziqah et al. 2018a).

Studies from Japan, Egypt, and Spain using agar-slant medium, STS primers, and sequencing respectively did not detect Blastocystis infection in dogs and cats (Abe et al. 2002; Mokhtar and Youssef 2018; and Paulos et al. 2018). Carnivores, including dogs and cats, screened in the UK, France, and Croatia by sequencing were also reported negative for Blastocystis infection (Alfellani et al. 2013). Conversely, a research in 2018 by Moura et al. showed $0 \%$ and $2.6 \%$ Blastocystis infection in pet cats and dogs respectively by sedimentation technique; these samples were found negative when screened by PCR-STS. It is suggested that dogs are not natural hosts for Blastocystis but rather are transiently and opportunistically infected with a diversity of STs (Wang et al. 2013) and do not play a significant role as natural reservoirs of human infection (Paulos et al. 2018).

Dogs and cats in ASEAN countries have been indicated to carry ST1-ST5, ST8, and ST10. Stensvold et al. identified ST3 in a dog in Denmark in 2009, ST1-ST3 were also described in several members of the order Carnivora in French zoos by Cian et al. (2017). 


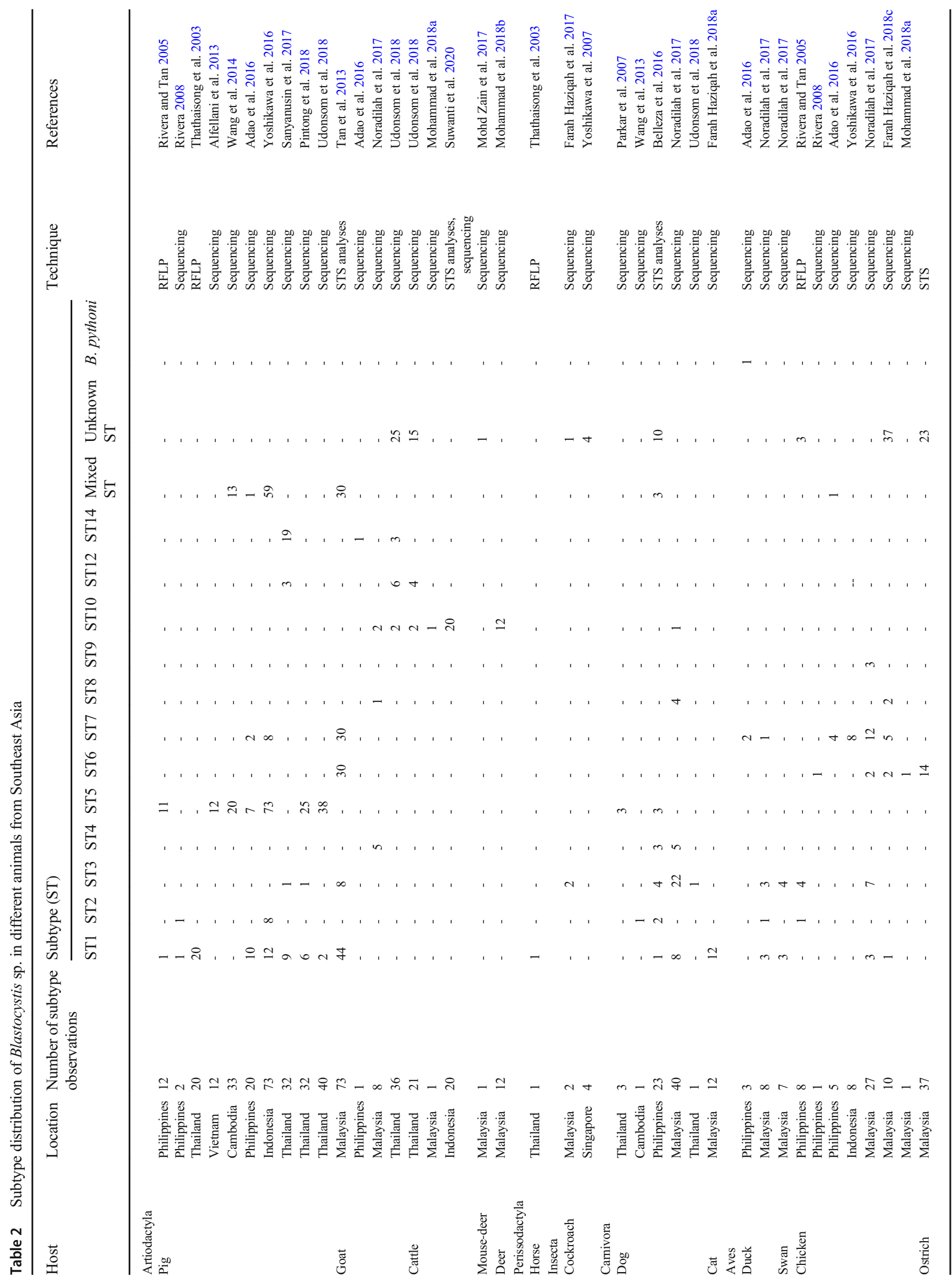




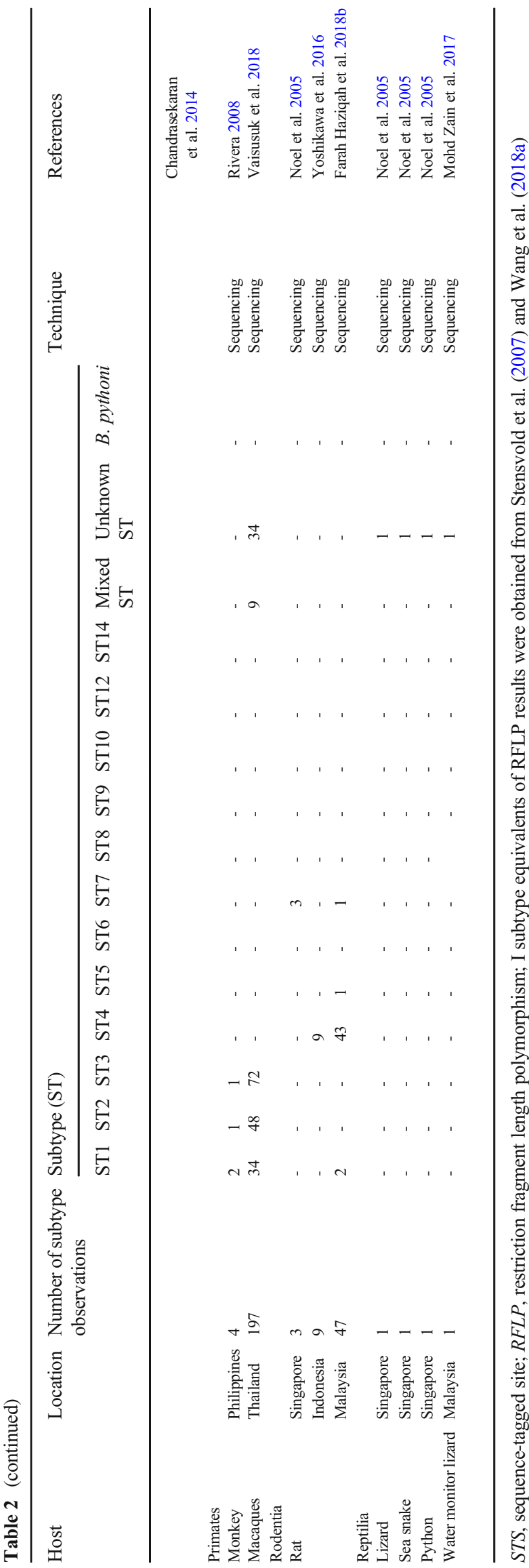

\section{Aves}

Blastocystis has been isolated from chicken, ostrich, duck, swan, and crow in Southeast Asia; all birds examined were from domestic environments. While chickens were the most studied, a prevalence of $100 \%$ was reported in ostriches and a range from 3.8 to $40 \%$ in the other birds (Table 1). These figures are comparable with records from Australia (Stenzel et al. 1994), Brazil (Bergamo do Bomfim and Machado do Couto 2013; Zanetti et al. 2020), Iran (Asghari et al. 2019), and Lebanon (Greige et al. 2018). In Malaysia, the prevalence of Blastocystis infection among free-range chickens was reported to be significantly higher than that of barn-reared chickens due to exposure of free-range chickens by their scavenging habits to environmental contamination (Farah Haziqah et al. 2014).

ST6 and ST7 were the predominant Avian STs in Southeast Asia; however, ST1, ST2, ST3, ST8, and ST9 were also identified. This finding is consistent with reports from Stensvold et al. (2009), Alfellani et al. (2013), Ramírez et al. (2014), Mokhtar and Youssef (2018), Greige et al. (2018), Wang et al. (2018b), and Deng et al. (2019). It is important to note the presence of ST9, a supposedly human subtype, in chicken in Malaysia, as reported by Noradilah et al. (2017).

\section{Insecta}

The presence of Blastocystis has been documented in cockroaches in Southeast Asia with a prevalence rate ranging from 10 to $80 \%$ (Table 1), and a significantly higher infection in nymphs than in adults reported by Farah Haziqah et al. (2017). So far, the only identified Blastocystis subtype in cockroaches in this region is ST3 by Farah Haziqah et al. (2017). Cian et al. (2017) have reported the presence of ST1-3 in roaches and locust, while ST4 was described in cockroaches by ValençaBarbosa et al. (2019). The observation of STs 1-4 is worrisome as cockroaches are ubiquitous, and these STs are the main subtypes infecting man, indicating that cockroaches could serve as a potential source of human infection.

\section{Rodentia}

Rats have been described as positive for Blastocystis infection, with ST1, ST4, ST5, and ST7 identified. These subtypes have also been reported in rodents elsewhere (Yoshikawa et al. 2004; Cian et al. 2017, Wang et al. 2018b; Betts et al. 2020), emphasizing the high prevalence of zoonotic ST4 within the rodent population.

\section{Reptilia}

Although house lizards, water monitor lizards, crocodiles, snakes, iguana, and tortoises have presented with 
Blastocystis infection with varying frequency of infection, studies have yet to identify the STs in them.

\section{Primates}

Blastocystis infection has been found in orangutan, macaque, and monkeys. The occurrence was 50\% and below, and only ST1, ST2, and ST3 were identified in macaque and monkey. These STs have been documented for macaque, monkeys, and other primates in Europe (Scicluna et al. 2006; Stensvold et al. 2009; Cian et al. 2017, Betts et al. 2020) and Brazil (ValençaBarbosa et al. 2019). ST4, ST5, and ST8 have also been identified in monkeys elsewhere (Yoshikawa et al. 2004; Scicluna et al. 2006; Stensvold et al. 2009, Valença-Barbosa et al. 2019).

\section{Conclusion}

An upsurge in the studies of Blastocystis infection in animals has been observed in Southeast Asia over the last decade. Molecular methods for detecting this organism have also been adopted, leading to the identification of subtypes available in various animal groups, thereby improving knowledge of Blastocystis sp. epidemiology.

Studies on the occurrence of Blastocystis sp. in at least one animal group have been carried out in seven of the eleven ASEAN countries. The majority of these studies have been from Malaysia, with livestock and poultry animals being the most examined. Twelve Blastocystis sp. subtypes: ST1, ST2, ST3, ST4, ST5, ST6, ST7, ST8, ST9, ST10, ST12, and ST14 have been identified in Southeast Asia. ST5 was the most dominant of them and was isolated mostly from pigs. Next to ST5 is ST1, which contrarily, has been found across many animal groups. Most of the subtypes identified were those commonly reported in man, an indication of the possibility of animal-to-man transmission. Common practice in Southeast Asia is the keeping of cats and dogs as companion animals, and intensive farming of livestock and poultry for cheap protein sources. In the course of handling and grooming their animals and during meat processing, pet owners and pig and poultry farmers may be at risk for Blastocystis infection. Generally, these animal handlers are encouraged to engage in good hygiene practices to reduce this risk.

Molecular techniques employed in the detection of subtypes varied from the use of restriction fragment length polymorphism (RFLP) to sequence-tagged site (STS) primers and then to the sequencing of partial or full SSU rDNA genes. For the prevalence of Blastocystis sp. in various animal groups and human populations to be accurately depicted, there is a need for uniformity in the diagnostic techniques employed in reported surveys.

In studies that considered for the exhibition of symptoms, animals were either reported as not showing symptoms or showed symptoms that did not correlate with infection. Nonetheless, the consistent presence of particular subtypes in livestock and poultry (ST5 in pigs, ST6 and 7 in poultry, and ST10 in cattle) is worth exploring. Studies are needed regarding the potential impact of Blastocystis on the wellbeing and productivity of infected animals. Also to be investigated is the impact of Blastocystis on the composition of gut microbiota and $\mathrm{pH}$ (and vice versa) in different animal hosts. Results from such investigations could provide insight into why infection with Blastocystis is rare in certain species, such as cats, dogs, and horses, and the host specificity of STs in general.

It is encouraged that additional investigation on Blastocystis sp. in diverse animal hosts and from other parts of Southeast Asia is carried out to provide a richer representation of the epidemiology of Blastocystis in this region. The use of adequate sample sizes in these studies is important. Overall, long-term studies are required to establish the incidence of Blastocystis in humans and animals in the same populations at the same time. The aim will be to assess whether these animals contaminate the food and water, thus transmitting Blastocystis infection to humans; this will help to confirm the actual risk of zoonotic transmission. Detailed genome studies, especially on STs shared by humans and animals, are also recommended to show the degree of similarity or variation within these STs.

Acknowledgements The authors would like to thank the team members in the Veterinary Parasitology Laboratory, Universiti Sains Malaysia who have helped in carrying out this review.

Author contributions This review was the idea of Meor Termizi Farah Haziqah. The first draft of the manuscript was written by Adedolapo Aminat Rauff-Adedotun and revised by Meor Termizi Farah Haziqah and Siti Nursheena Mohd Zain. All authors read and approved the final manuscript.

Funding This work was supported by Universiti Sains Malaysia (Short Term Grant 2018: 304/PBIOLOGI/6315156 and Postgraduate Research Grant Scheme: 1001.PBIOLOGI.AUPS001).

\section{Compliance with ethical standards}

Conflict of interest The authors declare that they have no conflict of interest.

Ethical approval Not applicable.

Consent to participate Not applicable.

Consent for publication Not applicable. 


\section{References}

Abe N, Nagoshi M, Takami K, Sawano Y, Yoshikawa H (2002) A survey of Blastocystis sp. in livestock, pets, and zoo animals in Japan. Vet Parasitol 106:203-212

Adao DEV, Rivera WL (2018) Recent advances in Blastocystis sp. research. Philipp Sci Lett 11:39-60. https://doi.org/10.1136/bmj.320. 7246.1385

Adao DEV, Ducusin RJT, Padilla MA, Rivera WL (2016) Molecular characterization of Blastocystis isolates infecting farm animals in Victoria and Pila, Laguna, Philippines. Philip Agric Sci 99:304-310

Adrus M, Zainudin R, Ahamad M, Jayasilan MA, Abdullah MT (2019) Gastrointestinal parasites of zoonotic importance observed in the wild, urban, and captive populations of non-human primates in Malaysia. J Med Primatol 48:22-31. https://doi.org/10.1111/jmp. 12389

Ahmed SA, Karanis P (2018) Blastocystis spp., ubiquitous parasite of human, animals and environment. 2nd edn. Elsevier Inc

Alfellani MA, Taner-Mulla D, Jacob AS, Imeede CA, Yoshikawa H, Stensvold CR, Clark CG (2013) Genetic diversity of Blastocystis in livestock and zoo animals. Protist 164:497-509. https://doi.org/ 10.1016/j.protis.2013.05.003

Asghari A, Sadraei J, Pirestani M, Mohammadpour I (2019) First molecular identification and subtype distribution of Blastocystis sp. isolated from hooded crows (Corvus cornix) and pigeons (Columba livia) in Tehran Province, Iran. Comp Immunol Microbiol Infect Dis 62: 25-30. https://doi.org/10.1016/j.cimid.2018.11.013

Belleza MLB, Reyes JCB, Tongol-Rivera PN, Rivera WL (2016) Subtype analysis of Blastocystis sp. isolates from human and canine hosts in an urban community in the Philippines. Parasitol Int 65: 291-294. https://doi.org/10.1016/j.parint.2016.02.009

Bergamo do Bomfim TC, Machado do Couto MC (2013) Morphological diagnosis and occurrence of Blastocystis spp. obtained from the stool samples of domestic bird species commercialized in municipal markets. J Parasitol Vector Biol 5:20-26. https://doi.org/10.5897/ JPVB12.014

Betts E, Gentekaki E, Tsaousis A (2020) Exploring micro-eukaryotic diversity in the gut: co-occurrence of Blastocystis subtypes and other microbial "parasites" in zoo animals. Front Microbiol 11:288. https://doi.org/10.3389/fmicb.2020.00288

Bordier M, Roger F (2013) Zoonoses in South-East Asia: a regional burden, a global threat. Anim Health Res Rev 14:40-67. https:// doi.org/10.1017/S1466252313000017

Casim LF, Bandal MZ, Gonzales JCB et al (2015) Enteroparasites of captive long-tailed macaques (Macaca fascicularis) from National Wildlife Research and Rescue Center, Diliman, Quezon City, Philippines. Asian J Conserv Biol 4:54-61

Chandrasekaran H, Govind SK, Panchadcharam C, Bathmanaban P, Raman K, Thergarajan G (2014) High lipid storage in vacoular forms of subtype 6 Blastocystis sp. in ostrich. Parasites Vectors 7: 1-7. https://doi.org/10.1186/s13071-014-0469-7

Chuong LS, Suresh K, Mak JW, Init I, Kathijah O (1996) Prevalence of Blastocystis in animals from domesticated surroundings. Southeast Asian J Trop Med Public Health 27:850-852

Cian A, El Safadi D, Osman M, Moriniere R, Gantois N, BenamrouzVanneste S, Delgado-Viscogliosi P, Guyot K, Li LL, Monchy S, Noël C, Poirier P, Nourrisson C, Wawrzyniak I, Delbac F, Bosc S, Chabé M, Petit T, Certad G, Viscogliosi E (2017) Molecular epidemiology of Blastocystis sp. in various animal groups from two French zoos and evaluation of potential zoonotic risk. PLoS One 12(1):1-29. https://doi.org/10.1371/journal.pone.0169659

Clark CG, van der Giezen M, Alfellani MA, Stensvold CR (2013) Recent developments in Blastocystis research. Adv Parasitol 82:1-32. https://doi.org/10.1016/B978-0-12-407706-5.00001-0
Coker RJ, Hunter BM, Rudge JW, Liverani M, Hanvoravongchai P (2011) Emerging infectious diseases in Southeast Asia: regional challenges to control. Lancet 377:599-609. https://doi.org/10. 1016/S0140-6736(10)62004-1

De La Cruz CPP, Gorospe MM, Paller VGV (2016) Blastocysts infection among backyard-raised pigs in bay, province of Laguna, the Philippines. Asian J Microbiol Biotechnol Environ Sci 18:209-217

Deng L, Chai Y, Zhou Z, Liu H, Zhong Z, Hu Y, Fu H, Yue C, Peng, G (2019) Epidemiology of Blastocystis sp infection in China: a systematic review. Parasite, 26(41). https://doi.org/10.1051/parasite/ 2019042REVIEW

Duda A, Stenzel DJ, Boreham PFL (1998) Detection of Blastocystis sp. in domestic dogs and cats. Vet Parasitol 76:9-17. https://doi.org/10. 1016/S0304-4017(97)00224-0

Farah Haziqah MT, Chandrawathani P, Mohd ZSN et al (2014) A preliminary study of Blastocystis sp. isolated from chicken in Perak and Selangor, Malaysia. Malays J Vet Res 5:21-25

Farah Haziqah MT, Nur Asyiqin MN, Mohd Khalid MKN et al (2017) Current status of Blastocystis in cockroaches. Trop Biomed 34:741745

Farah Haziqah MT, Chandrawathani P, Douadi B et al (2018a) Impact of $\mathrm{pH}$ on the viability and morphology of Blastocystis isolates. Trop Biomed 35:501-510

Farah Haziqah MT, Chandrawathani P, Suresh KG et al (2018b) Prevalence, ultrastructure and subtypes of Blastocystis in chickens (Gallus gallus) from Peninsular Malaysia. Southeast Asian J Trop Med Public Health 49:921-932

Farah Haziqah MT, Mohd Zain SN, Chandrawathani P et al (2018c) Genetic diversity of rodent Blastocystis sp. from Peninsular Malaysia. Trop Biomed 35:586-592

Fayer R, Santin M, MacArisin D (2012) Detection of concurrent infection of dairy cattle with Blastocystis, Cryptosporidium, Giardia, and Enterocytozoon by molecular and microscopic methods. Parasitol Res 111(3):1349-1355. https://doi.org/10.1007/s00436-012-2971-1

Greige S, El Safadi D, Bécu N et al (2018) Prevalence and subtype distribution of Blastocystis sp. isolates from poultry in Lebanon and evidence of zoonotic potential. Parasites Vectors 11:1-10. https://doi.org/10.1186/s13071-018-2975-5

Greige S, El Safadi D, Khaled S, Gantois N, Baydoun M, Chemaly M, Benamrouz-Vanneste S, Chabé M, Osman M, Certad G, Hamze M, Viscogliosi E (2019) First report on the prevalence and subtype distribution of Blastocystis sp. in dairy cattle in Lebanon and assessment of zoonotic transmission. Acta Trop 194:23-29. https://doi. org/10.1016/j.actatropica.2019.02.013

Hastutiek P, Yuniarti WM, Djaeri M et al (2019) Prevalence and diversity of gastrointestinal protozoa in Madura cattle at Bangkalan Regency, East Java, Indonesia. Vet World 12:198-204. https://doi.org/10. 14202/vetworld.2019.198-204

Hemalatha C, Chandrawathani P, Suresh Kumar G et al (2014) The diagnosis of Blastocystis sp. from animals - an emerging zoonosis. Malays J Vet Res 5:15-22

Jones-Engel L, Engel GA, Schillaci MA, Froehlich J, Paputungan U, Kyes RC (2004) Prevalence of enteric parasites in pet macaques in Sulawesi, Indonesia. Am J Primatol 62:71-82. https://doi.org/10. 1002/ajp. 20008

Labes EM, Hegglin D, Grimm F et al (2010) Intestinal parasites of endangered orangutans (Pongo pygmaeus) in Central and East Kalimantan, Borneo, Indonesia. Parasitology 137:123-135. https:// doi.org/10.1017/S0031182009991120

Lee HY, Ambu S, Devi S, Maung M (2008) Detection of protozoan and bacterial pathogens of public health importance in faeces of Corvus spp. (large-billed crow). Trop Biomed 25:134-139

Leelayoova S, Siripattanapipong S, Naaglor T et al (2009) Prevalence of intestinal parasitic infections in military personnel and military dogs Thailand. J Med Assoc Thail 92(Suppl 1):53-59 
Lim YAL, Ngui R, Shukri J, Rohela M, Mat Naim HR (2008) Intestinal parasites in various animals at a zoo in Malaysia. Vet Parasitol 157: 154-159. https://doi.org/10.1016/j.vetpar.2008.07.015

Masuda A, Sumiyoshi T, Ohtaki T, Matsumoto J (2018) Prevalence and molecular subtyping of Blastocystis from dairy cattle in Kanagawa, Japan. Parasitol Int 67(6):702-705. https://doi.org/10.1016/j.parint. 2018.07.005

Mohammad NA, Al-Mekhlafi HM, Anuar TS (2018a) Subtype distribution of Blastocystis isolated from humans and associated animals in an indigenous community with poor hygiene in Peninsular Malaysia. Trop Biomed 35:849-860

Mohammad NA, Al-Mekhlafi HM, Moktar N, Anuar TS (2018b) Molecular detection and subtyping of Blastocystis in Javan rusa (Cervus timorensis) and sika deer (Cervus nippon) from Peninsular Malaysia. Thai J Vet Med 48:295-301

Mohd Zain SN, Farah Haziqah MT, Woh PY et al (2017) Morphological and molecular detection of Blastocystis in wildlife from Tioman Island, Malaysia. Trop Biomed 34:249-255

Mokhtar A, Youssef A (2018) Subtype analysis of Blastocystis spp. isolated from domestic mammals and poultry and its relation to transmission to their in-contact humans in Ismailia governorate, Egypt. Parasitol United J 11:90-98. https://doi.org/10.21608/puj.2018. 16318

Moura RGF, de Oliveira-Silva MB, Pedrosa AL et al (2018) Occurrence of Blastocystis spp. in domestic animals in triângulo mineiro area of Brazil. Rev Soc Bras Med Trop 51:240-243. https://doi.org/10. 1590/0037-8682-0484-2016

Nieves-Ramirez ME, Partida-Rodriguez O, Laforest-Lapointe LA et al (2018) Asymptomatic intestinal colonization with Protist Blastocystis. Host-Microbe Biol 3:1-18

Noel C, Dufernez F, Gerbod D et al (2005) Molecular phylogenies of Blastocystis isolates from different hosts: implications for genetic diversity, identification of species, and zoonosis. J Clin Microbiol 43:348-355. https://doi.org/10.1128/jcm.43.1.348-355.2005

Noradilah SA, Anuar TS, Moktar N et al (2017) Molecular epidemiology of Blastocystis sp. in animals reared by the aborigines during wet and dry seasons in rural communities, Pahang, Malaysia. Southeast Asian J Trop Med Public Health 48:1151-1160

Parkar U, Traub RJ, Kumar S et al (2007) Direct characterization of Blastocystis from faeces by PCR and evidence of zoonotic potential. Parasitology 134:359-367. https://doi.org/10.1017/ S0031182006001582

Patagi AL, Suwanti LT, Chairul A et al (2018) Prevalance of gastrointestinal protozoa of cats in animal hospital and animal clinic in Surabaya. J Parasite Sci 2:61-66

Paulos S, Köster PC, de Lucio A, Hernández-de-Mingo M, Cardona GA, Fernández-Crespo JC, Stensvold CR, Carmena D (2018) Occurrence and subtype distribution of Blastocystis sp. in humans, dogs and cats sharing household in northern Spain and assessment of zoonotic transmission risk. Zoonoses Public Health 65:9931002. https://doi.org/10.1111/zph.12522

Pintong A, Sunyanusin S, Prasertbun R, Mahittikorn A, Mori H, Changbunjong T, Komalamisra C, Sukthana Y, Popruk S (2018) Blastocystis subtype 5: predominant subtype on pig farms, Thailand. Parasitol Int 67:824-828. https://doi.org/10.1016/j.parint. 2018.08.009

Prasetyo RH (2016) Survey of house rat intestinal parasites from Surabaya District, East Java, Indonesia that can cause opportunistic infections in humans. Southeast Asian J Trop Med Public Health 47: 194-198

Premaalatha B, Chandrawathani P, Priscilla FX et al (2017) A survey of endoparasite and ectoparasite infections of wild rats caught in areas of Ipoh and Kuala Lumpur, Malaysia. Malays J Vet Res 8:29-34

Ramírez JD, Sánchez LV, Bautista DC, Corredor AF, Flórez AC, Stensvold CR (2014) Blastocystis subtypes detected in humans and animals from Colombia. Infect Genet Evol 22:223-228. https://doi.org/10.1016/j.meegid.2013.07.020

Rivera WL (2008) Phylogenetic analysis of Blastocystis isolates from animal and human hosts in the Philippines. Vet Parasitol 156:178 182. https://doi.org/10.1016/j.vetpar.2008.06.001

Rivera WL, Tan MAV (2005) Molecular characterization of Blastocystis isolates in the Philippines by riboprinting. Parasitol Res 96:253257. https://doi.org/10.1007/s00436-005-1344-4

Sanyanusin S, Mori H, Prasertbun R, et al (2017) Molecular detection and genotyping of Blastocystis and Enterocytozoon bieneusi in humans and pigs in Nakhon Pathom province, Thailand. Jt Int Trop Med Meet Proc 6:1-6

Scicluna SM, Tawari B, Clark CG (2006) DNA barcoding of Blastocystis. Protist 157(1):77-85. https://doi.org/10.1016/j.protis. 2005.12.001

Silberman JD, Sogin ML, Leipe DD, Clark CG (1996) Human parasite finds taxonomic home. Nature 380:398. https://doi.org/10.1038/ $380398 \mathrm{a} 0$

Skotarczak B (2018) Genetic diversity and pathogenicity of Blastocystis. Ann Agric Environ Med 25:411-416. https://doi.org/10.26444/ aaem $/ 81315$

Song JK, Yin YL, Yuan YJ, Tang H, Ren GJ, Zhang HJ, Li ZX, Zhang YM, Zhao GH (2017) First genotyping of Blastocystis sp. in dairy, meat, and cashmere goats in northwestern China. Acta Trop 176: 277-282. https://doi.org/10.1016/j.actatropica.2017.08.028

Stensvold CR, Suresh GK, Tan KSW, Thompson RCA, Traub RJ, Viscogliosi E, Yoshikawa H, Clark CG (2007) Terminology for Blastocystis subtypes - a consensus. Trends Parasitol 23:93-96. https://doi.org/10.1016/j.pt.2007.01.004

Stensvold CR, Alfellani MA, Nørskov-Lauritsen S, Prip K, Victory EL, Maddox C, Nielsen HV, Clark CG (2009) Subtype distribution of Blastocystis isolates from synanthropic and zoo animals and identification of a new subtype. Int J Parasitol 39:473-479. https://doi.org/ 10.1016/j.ijpara.2008.07.006

Stensvold CR, Alfellani M, Clark CG (2012) Levels of genetic diversity vary dramatically between Blastocystis subtypes. Infect Genet Evol 12:263-273. https://doi.org/10.1016/j.meegid.2011.11.002

Stensvold CR, Tan KSW, Clark CG (2020) Blastocystis. Trends Parasitol 36:2019-2020. https://doi.org/10.1016/j.pt.2019.12.008

Stenzel DJ, Cassidy MF, Boreham PFL (1994) Morphology of Blastocystis sp. from domestic birds. Parasitol Res 80(2):131-137. https://doi.org/10.1007/BF00933780

Suresh K, Mak JW, Chuong LS, Ragunathan T, Init I (1997) Sac-like pouches in Blastocystis from the house lizard Cosymbotus platyurus. Parasitol Res 83:523-525. https://doi.org/10.1007/ s004360050292

Susana Y, Suwanti LT, Suprihati E (2019) Identification and prevalence of gastrointestinal parasites in beef cattle in Siak Sri Indrapura, Riau, Indonesia. Indones J Trop Infect Dis 7:155-160. https://doi.org/10. 20473/ijtid.v7i6.10392

Suwanti LT, Susana Y, Hastutiek P et al (2020) Blastocystis spp. subtype 10 infected beef cattle in Kamal and Socah, Bangkalan, Madura, Indonesia. Vet World 13:231-237. https://doi.org/10.14202/ vetworld.2020.231-237

Tan KSW (2004) Blastocystis in humans and animals: new insights using modern methodologies. Vet Parasitol 126:121-144. https://doi.org/ 10.1016/j.vetpar.2004.09.017

Tan KSW (2008) New insights on classification, identification, and clinical relevance of Blastocystis spp. Clin Microbiol Rev 21:639-665. https://doi.org/10.1128/CMR.00022-08

Tan KSW, Singh M, Yap EH (2002) Recent advances in Blastocystis hominis research: hot spots in terra incognita. Int $\mathrm{J}$ Parasitol 32: 789-804. https://doi.org/10.1016/S0020-7519(02)00005-X

Tan TC, Tan PC, Sharma R, Sugnaseelan S, Suresh KG (2013) Genetic diversity of caprine Blastocystis from Peninsular Malaysia. Parasitol Res 112:85-89. https://doi.org/10.1007/s00436-012-3107-3 
Teow WL, Zaman V, Ng GC, Chan YC, Yap EH, Howe J, Gopalakrishnakone P, Singh M (1991) A Blastocystis species from the sea-snake, Lapemis hardwickii (Serpentes: Hydrophiidae). Int J Parasitol 21:723-726. https://doi.org/10.1016/0020-7519(91) 90086-M

Teow WL, Ng GC, Chan PP, Chan YC, Yap EH, Zaman V, Singh M (1992) A survey of Blastocystis in reptiles. Parasitol Res 78:453455. https://doi.org/10.1007/BF00931705

Thathaisong U, Worapong J, Mungthin M, Tan-Ariya P, Viputtigul K, Sudatis A, Noonai A, Leelayoova S (2003) Blastocystis isolates from a pig and a horse are closely related to Blastocystis hominis. J Clin Microbiol 41:967-975. https://doi.org/10.1128/JCM.41.3. 967

Udonsom R, Prasertbun R, Mahittikorn A, Mori H, Changbunjong T, Komalamisra C, Pintong AR, Sukthana Y, Popruk S (2018) Blastocystis infection and subtype distribution in humans, cattle, goats, and pigs in central and western Thailand. Infect Genet Evol 65:107-111. https://doi.org/10.1016/j.meegid.2018.07.007

Vaisusuk K, Saijuntha W, Sedlak S, Thanchomnang T, Pilap W, Suksavate W, Stensvold CR, Tantrawatpan C (2018) Blastocystis subtypes detected in long-tailed macaques in Thailand-further evidence of cryptic host specificity. Acta Trop 184:78-82. https://doi. org/10.1016/j.actatropica.2017.09.002

Valença-Barbosa C, Do Bomfim TCB, Teixeira BR, Gentile R, Da Costa Neto SF, Magalhães BSN, De Almeida BD, Da Silva FA, Biot R, D'Avila Levy CM, Santos HLC (2019) Molecular epidemiology of Blastocystis isolated from animals in the state of Rio de Janeiro, Brazil. PLoS One 14(1):1-13. https://doi.org/10.1371/journal. pone. 0210740

Wang W, Cuttell L, Bielefeldt-Ohmann H, Inpankaew T, Owen H, Traub RJ (2013) Diversity of Blastocystis subtypes in dogs in different geographical settings. Parasites Vectors 6:215-219. https://doi.org/ 10.1186/1756-3305-6-215

Wang W, Owen H, Traub RJ, Cuttell L, Inpankaew T, BielefeldtOhmann H (2014) Molecular epidemiology of Blastocystis in pigs and their in-contact humans in Southeast Queensland, Australia, and
Cambodia. Vet Parasitol 203:264-269. https://doi.org/10.1016/j. vetpar.2014.04.006

Wang J, Gong B, Yang F, Zhang W, Zheng Y, Liu A (2018a) Subtype distribution and genetic characterizations of Blastocystis in pigs, cattle, sheep and goats in northeastern China's Heilongjiang Province. Infect Genet Evol 57:171-176. https://doi.org/10.1016/j. meegid.2017.11.026

Wang J, Gong B, Liu X, Zhao W, Bu T, Zhang W, Liu A, Yang F (2018b) Distribution and genetic diversity of Blastocystis subtypes in various mammal and bird species in northeastern China. Parasites Vectors 11(1):1-7. https://doi.org/10.1186/s13071-018-3106-Z

Yoshikawa H, Abe N, Wu Z (2004) PCR-based identification of zoonotic isolates of Blastocystis from mammals and birds. Microbiology 150(5):1147-1151. https://doi.org/10.1099/mic.0.26899-0

Yoshikawa H, Wu Z, Howe J et al (2007) Ultrastructural and phylogenetic studies on Blastocystis isolates from cockroaches. J Eukaryot Microbiol 54:33-37. https://doi.org/10.1111/j.1550-7408.2006. 00141.x

Yoshikawa H, Tokoro M, Nagamoto T, Arayama S, Asih PBS, Rozi IE, Syafruddin D (2016) Molecular survey of Blastocystis sp. from humans and associated animals in an Indonesian community with poor hygiene. Parasitol Int 65:780-784. https://doi.org/10.1016/j. parint.2016.03.010

Zaman V, Ng GC, Suresh K, Yap EH, Singh M (1993) Isolation of Blastocystis from the cockroach (Dictyoptera: Blattidae). Parasitol Res 79:73-74. https://doi.org/10.1007/bf00931221

Zanetti ADS, Malheiros AF, de Matos TA, Longhi FG, Moreira LM, Silva SL, Castrillon SKI, Ferreira SMB, Ignotti E, Espinosa OA (2020) Prevalence of Blastocystis sp. infection in several hosts in Brazil: a systematic review and meta-analysis. Parasites Vectors 13(1):30. https://doi.org/10.1186/s13071-020-3900-2

Publisher's note Springer Nature remains neutral with regard to jurisdictional claims in published maps and institutional affiliations. 